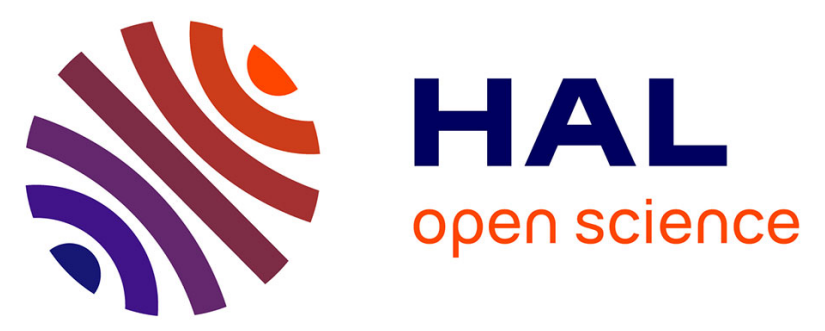

\title{
Is There a Place for the Posterior Approach in Cases of Acute Myelopathy on Thoracic Disc Hernia?
}

\author{
David Brauge, Rachid Madkouri, Vincent Reina, Saad Bennis, Bertrand \\ Baussart, Etienne Mireau, Sorin Aldea, Stephan Gaillard
}

\section{- To cite this version:}

David Brauge, Rachid Madkouri, Vincent Reina, Saad Bennis, Bertrand Baussart, et al.. Is There a Place for the Posterior Approach in Cases of Acute Myelopathy on Thoracic Disc Hernia?. World Neurosurgery, 2017, 107, pp.744-749. 10.1016/j.wneu.2017.08.100 . hal-02496827

\section{HAL Id: hal-02496827 https://hal.science/hal-02496827}

Submitted on 3 Mar 2020

HAL is a multi-disciplinary open access archive for the deposit and dissemination of scientific research documents, whether they are published or not. The documents may come from teaching and research institutions in France or abroad, or from public or private research centers.
L'archive ouverte pluridisciplinaire HAL, est destinée au dépôt et à la diffusion de documents scientifiques de niveau recherche, publiés ou non, émanant des établissements d'enseignement et de recherche français ou étrangers, des laboratoires publics ou privés. 


\section{Is There a Place for the Posterior Approach in Cases of Acute Myelopathy on Thoracic Disc Hernia?

\author{
David Brauge $^{1,2}$, Rachid Madkouri ${ }^{1}$, Vincent Reina ${ }^{1}$, Saad Bennis ${ }^{1}$, Bertrand Baussart $^{1}$, Etienne Mireau $^{1}$, Sorin Aldea $^{1}$, \\ Stephan Gaillard ${ }^{1}$
}

BACKGROUND: Acute myelopathy in cases of thoracic disc herniation (TDH) is an exceptional condition for which the treatment is not codified. Here we present the results of a standardized procedure in 10 patients who underwent surgery for acute myelopathy on TDH between December 2009 and December 2016.

METHODS: Our approach began with a cautious Iaminectomy without resection of the hernia on the day of admission. On subsequent days, a complementary thoracoscopic procedure was performed according to the patient's neurologic recovery and the nature of the hernia (calcified or fibrous). Outcome was assessed by the Frankel score at the last consultation.

RESULTS: All patients had acute myelopathy, with Frankel score of $\mathrm{C}$ or worse and a TDH detected on magnetic resonance imaging occupying an average of $62.5 \pm 18.4 \%$ of the canal. This lesion was calcified in $\mathbf{6}$ cases and soft in 4 cases. The laminectomy allowed stabilization in 1 case and a neurologic improvement in $\mathbf{9}$ cases. Complementary surgery via a thoracoscopic approach was performed in the 6 cases of calcified hernia. After an average follow-up of $\mathbf{4 4 . 5 5}$ \pm 26.44 months, 6 patients showed complete neurologic recovery and 4 had moderate sequelae (Frankel D).

CONCLUSIONS: Laminectomy appears to allow stabilization of the neurologic situation in rare cases of acute myelopathy on TDH. The need for complementary resection of the hernia by an anterior approach should always be discussed secondarily.

\footnotetext{
Key words

- Acute myelopathy

- Hernia calcified or fibrous

- Laminectomy

- Thoracic disc herniation

- Treatment
}

Abbreviations and Acronyms

MRI: Magnetic resonance imaging

TDH: Thoracic disc herniation

\section{INTRODUCTION}

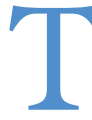
horacic disc herniation (TDH) is a common anatomic lesion but rarely has clinical consequences necessitating surgical intervention. This pathology accounts for only $0.5 \%$ of herniated disc surgeries, corresponding to an incidence of I case per million. ${ }^{\mathrm{I}, 2}$ The most common symptoms are intercostal neuralgia and progressive myelopathy. In highly symptomatic cases, most authors propose surgical removal of the hernia. Laminectomy was the first approach described for the resection of these lesions, ${ }^{3}$ but was gradually abandoned because of high neurologic morbidity. Currently, several techniques are performed, according to the location of the hernia and the preference of the operator..$^{4-7}$

In exceptional cases, the hernia can be accompanied by acute myelopathy. This situation, the frequency of which is poorly documented, corresponds to 2 distinct anatomoclinical entities: a soft hernia that is ejected, usually posterolaterally because of the presence of the posterior longitudinal ligament, or a calcified hernia that is revealed acutely. To the best of our knowledge, apart from case reports, there is only I previous report of a series of 8 patients in this situation. ${ }^{8}$ That single study left several questions unanswered: what is the ideal time to deal with the problem? What surgical technique is available in an emergency? What is the long-term prognosis for these patients? Here we report our experience in a series of Io patients who underwent emergency surgery for acute myelopathy due to TDH. The treatment strategy and the neurologic evolution are described in detail.

\section{METHODS}

Study Design and Inclusion Criteria

Here we present a monocentric, retrospective series of patients initially referred for acute myelopathy due to TDH. The inclusion

From the ${ }^{1}$ Service de Neurochirurgie, Hôpital Foch, Suresnes; and ${ }^{2}$ Institut de Biomécanique Humaine Georges Charpak Arts et Métiers Paris Tech, Paris, France

To whom correspondence should be addressed: David Brauge, M.D.

[E-mail:d.brauge@hopital-foch.com] 
criteria were myelopathy in relation to TDH, Frankel score of $\mathrm{C}$ or greater, and a neurologic disorder evolving for up to I week. In all cases, TDH was diagnosed based on preoperative magnetic resonance imaging (MRI) findings. The postoperative follow-up was at least 3 months for each case. The primary endpoint was Frankel score at last follow-up.

The records were obtained from a database of 69 patients who underwent surgery in our department between May I, 200I, and December 3I, 20I6, for TDH. Ten patients met the inclusion criteria, representing $14.5 \%$ of our patients who underwent a surgical procedure for TDH.

\section{Treatment Strategy}

Our hospital's Department of Neurosurgery has developed expertise in surgery for TDH, and the management of the exceptional situation of acute myelopathy is well codified. Once the diagnosis has been made following a spinal MRI, the patient is taken in charge urgently by the on-call neurosurgeon. After clinical examination and confirmation of the diagnosis of severe myelopathy due to TDH (Frankel C or worse), the patient is transferred to the operating theater. An extremely cautious laminectomy is then performed with respect to the stenotic zone. This is only a posterior decompressive procedure, with no attempt made to resect the hernia. No mobilization of the spinal cord is performed during this intervention. The extension of decompression to the articular facet via arthrodesis is left to the discretion of the operator.

Postoperatively, the patient is verticalized early, with rehabilitation work by a physiotherapist. If the hernia is calcified, a second intervention is systematically performed via thoracoscopy, with the intent of resecting the hernia during the same hospitalization. In cases with a soft herniation, the patient is closely monitored after surgery, with discharge after Io days in the event of favorable evolution. In patients who show no neurologic improvement or worsening symptoms, a second surgery via an anterior approach is considered.

\section{Description of the Series}

Our cohort comprised to patients who underwent surgery between December 2009 and December 20I6. The mean patient age at the time of management was 56.I \pm I2.I years, and the sex ratio was I:I. At admission, 8 patients had a Frankel score of C, and 2 patients had a Frankel score of B. Six patients had sphincter disorders, 2 patients had no other disorder, and 2 patients had no information on this item in the initial observation. The site of the lesion was T6-T7 in I case, T7-T8 in I case, T9-Tro in 4 cases, TroTII in 2 cases, TII-TI2 in I case, and TI2-LI in I case. The hernia was soft in 4 cases and calcified in 6 cases. The hernia occupied an average of $62.5 \pm 18.4 \%$ of the spinal canal. Four cases involved segmental posterior compression associated with hypertrophy of the posterior articular facets or ligamentum flavum.

\section{RESULTS}

All patients underwent laminectomy. The procedure took an average of $135 \pm 32.9$ minutes. The mean blood loss was I65 $\pm 70.9 \mathrm{~mL}$. No intraoperative complications were reported. Osteosynthesis with posterior arthrodesis was performed in 3 cases, all presenting soft hernias. All patients received a I20-mg bolus of methylprednisolone at the start of surgery. The 6 patients with calcified hernia decompensation underwent complementary anterior surgery via thoracoscopy within a mean of $49.6 \pm 45.7$ days. Resection was complete in 3 cases and subtotal (residual $<\mathrm{IO} \%$ of the initial lesion) in the other 3 cases. In I case, a transdural hernia was revealed during surgery. In the 4 cases of soft hernia, no complementary procedures were performed during follow-up, because neurologic recovery was total or subtotal. No patient exhibited a worsening Frankel score in the immediate postoperative period after laminectomy. The mean follow-up was $44.55 \pm 26.44$ months, with neurologic evolution as reported in Table 1. No patient presented with vesicosphincteric disorder at the last follow-up.

\section{Illustrative Cases}

Case 1. This 56-year-old male with no medical history (patient 8) reported sudden onset of dorsal pain after lifting a heavy object. On awakening the following day, he experienced a walking disorder and acute retention of urine, which prompted his presentation at the emergency department of the local hospital. Clinical examination revealed paraparesis of $3 / 5$ on the right and $4 / 5$ on the left, with a sensory level of Tro and urinary retention. Spinal MRI showed a large hernia at TI2-Li (Figure 1A and B). The patient was transferred to our unit for surgical treatment of this acute myelopathy. The procedure performed was a TI2-Li laminectomy extended to the left articular facet. Osteosynthesis with a pedicle screw and arthrodesis was performed at the same time. The procedure lasted a total of 157 minutes, with $200 \mathrm{~mL}$ of blood loss and no intraoperative complications.

The patient experienced neurologic improvement on waking. The postoperative scan confirmed the noncalcified nature of the hernia (Figure 1C and D). On discharge from the department on postoperative day I2, the patient still required assistance with walking and had a urinary catheter in place. When the situation was reviewed in consultation at 2 months, the patient had improved significantly but still needed crutches for walking. There was no longer any sphincter or sexual dysfunction. At an 8-month follow-up, recovery was almost complete, and the patient required only a cane for outdoor walking on long journeys. MRI revealed partial resorption of the hernia (Figure 1E and F).

Case 2. This 37-year-old female was diagnosed with a calcified T9-Io disc herniation after exploration of paraesthesia of the lower limbs and fatigability without walking limitation (patient I, Figure 2A and B). Clinically, she had a discrete limb deficit of $4+/ 5$. During the period preceding her operation, she was hospitalized for an exacerbation of neuropathic pain in the lower limbs associated with an aggravation of the motor deficit in her distal left limb and a contrololateral thermoalgic disorder which made standing difficult (Frankel score C). There was no history of any factor (e.g., minor trauma) that could explain this deterioration. A new MRI was performed and was superimposable on the previous images; therefore, we performed an emergency posterior decompression without instrumentation. This stabilized the neurologic degradation and eliminated the pain (Figure 2C and D). Reoperation was performed on the fourth postoperative day via an anterior 
Table 1. Neurologic Outcomes After Surgery

\begin{tabular}{|c|c|c|c|c|c|c|}
\hline Patient & $\begin{array}{l}\text { Type of } \\
\text { Herniation }\end{array}$ & $\begin{array}{l}\text { Posterior Segmental } \\
\text { Stenosis }\end{array}$ & $\begin{array}{l}\text { Preoperative } \\
\text { Frankel }\end{array}$ & $\begin{array}{c}\text { Postlaminectomy } \\
\text { Frankel }\end{array}$ & $\begin{array}{l}\text { Frankel at Last } \\
\text { Follow-Up }\end{array}$ & $\begin{array}{c}\text { Follow-Up } \\
\text { (months) }\end{array}$ \\
\hline 1 & Calcified & No & C & $E$ & $E$ & 49.6 \\
\hline 2 & Calcified & No & C & D & D & 54.9 \\
\hline 3 & Calcified & Yes & B & B & D & 41.8 \\
\hline 4 & Calcified & No & C & D & $E$ & 55.5 \\
\hline 5 & Calcified & No & C & D & $\mathrm{E}$ & 66.5 \\
\hline 6 & Calcified & Yes & C & D & $E$ & 88.4 \\
\hline 7 & Soft & No & C & $\mathrm{E}$ & $E$ & 5.4 \\
\hline 8 & Soft & No & B & D & D & 8.4 \\
\hline 9 & Soft & Yes & C & D & D & 18.9 \\
\hline 10 & Soft & Yes & C & $E$ & $E$ & 56.1 \\
\hline
\end{tabular}

thoracoscopic approach, which allowed complete resection of the lesion (Figure 2E and F). The immediate postoperative period was uncomplicated, and the patient returned home 7 days later. At 3 months, she had recovered completely, and her neuropathic pain had virtually disappeared with medical treatment.

\section{DISCUSSION}

Historically, laminectomy was the first approach described for resection of TDH. Later, spine surgeons developed other techniques (e.g., posterolateral approach by arthropediculectomy, lateral approach by costotransversectomy, anterior transthoracic approach). Several meta-analyses showed high rates of morbidity and mortality with laminectomy compared with the other techniques. ${ }^{9-I I}$ However, it is interesting to note that these literature reviews did not focus on the rare case of acute myelopathies due to TDH. In addition, laminectomy was evaluated by many of those authors as an approach allowing hernia resection. Because of the significant mobilization of the spinal cord required to access the thoracic disc space, neurologic morbidity is as high as $20 \%-60 \%$. The originality of our surgical procedure lies in the fact that we carry out initial surgery only solely at decompression, with no attempt to resect the hernia. This is not the case for other authors who have reported similar cases. ${ }^{\mathrm{II}-\mathrm{I} 8}$ Apart from these few case reports, the only published results of surgery for acute myelopathy due to TDH is the series reported by Cornips et al., ${ }^{8}$ who estimated the frequency of this condition at $4 \%$ of surgeries for $\mathrm{TDH}$, highlighting the rarity of this situation.

\section{Calcified Hernia vs Soft Hernia}

We believe that there are 2 situations with differing pathophysiology and evolution. The decompensation mechanism seems quite obvious for a soft hernia with an acute compression of the spinal cord. For calcified herniation, the decompensation factor remains unclear. Several hypotheses come to mind when reading case reports on this topic, including initial trauma, ${ }^{\mathrm{II}, \mathrm{I} 4}$ compression of the anterior spinal vascular axis, ${ }^{19,20}$ and acute inflammatory stage. ${ }^{18}$ In all cases, with the existence of medullary compression affirmed by MRI, there is a scientific rationale for performing emergency decompression surgery. ${ }^{21}$

For acute decompensation, posterior decompression seems to be sufficient in cases of soft hernia. All 4 patients with a soft hernia in our series were treated with a simple posterior intervention, 3 of them with instrumentation to optimize decompression by removal of articular process and prevent kyphosis induced by laminectomy. At the last follow-up, all exhibited total or subtotal neurologic recovery, which precluded the need for additional complementary surgery. For the 6 patients with a calcified herniation, this initial procedure stabilized or partially improved the neurologic state. As the normal curvature of the spine does not let the cord fall back but will continue to be dropped over the disc, in a second step, we performed anterior resection of the calcified hernia. In the series reported by Cornips et al., ${ }^{8}$ the one patient treated via an initial posterior approach had a calcified hernia and required additional surgery by the anterior route. Unfortunately, the authors did not provide details of the initial intervention, particularly whether the operator had made an attempt to remove the hernia or had merely enlarged the canal. On the other hand, anterior or posterolateral hernia resection is a technically challenging procedure. Dickman et al., ${ }^{22}$ in a series of patients who underwent reoperation due to an incomplete initial anterior approach, noted that this first procedure made the revision surgery more difficult. All of the foregoing findings lead us to believe that an initial posterior decompression surgery can stabilize or improve neurologic status in an emergency. In cases of calcified hernia, this makes it possible to perform complementary surgery via an anterior approach under optimal conditions.

\section{Timing of Second Surgery}

None of our patients benefited from discal resection via a transpedicular approach or a costotransversectomy in an emergency. Indeed, this is technically more challenging than laminectomy alone, especially for central location of the hernia. This type of procedure can be difficult and time-consuming in an emergency situation, especially for an operator not highly trained in spinal 


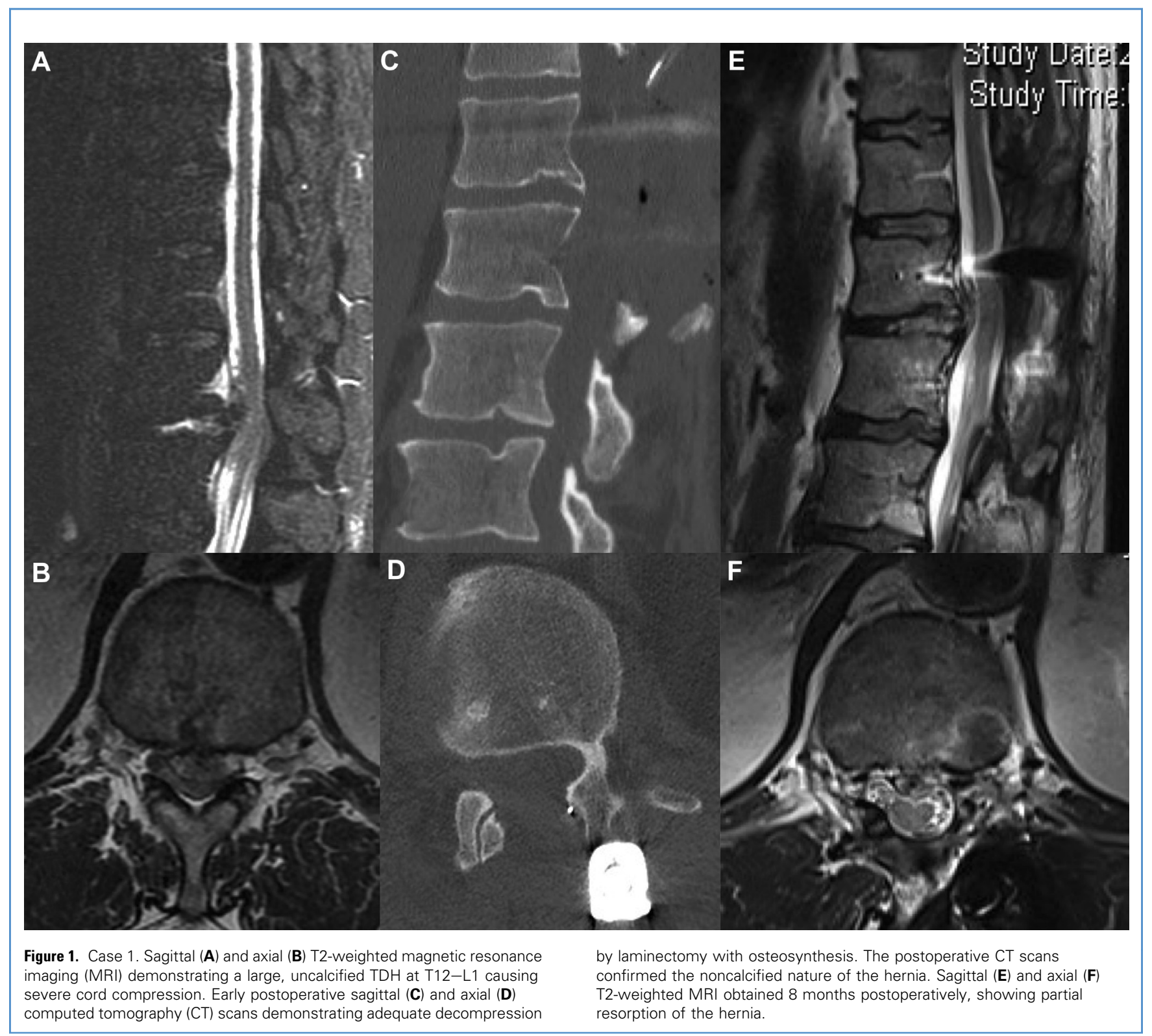

surgery. In addition, in a recent observational study, Wang et al. ${ }^{23}$ highlighted the importance of limiting the blood loss and the phases of hypotension in patients with thoracic myelopathy operated using a posterior approach. These findings suggest the importance of a rapid and less hemorrhagic procedure in an emergency.

The question of an anterior complementary resection is always discussed secondarily:

In cases of soft herniation, the patient is closely monitored during the days after the initial surgery. If recovery is noted, we prefer to take some time and continue to monitor the patient. Our strategy is to perform an anterior surgery only in patients with of incomplete recovery with disabling symptoms or worsening symptoms during follow-up. Over the past 7 years, we have treated only 4 patients with acute thoracic myelopathy due to soft herniation. None required anterior surgery, likely due to a spontaneous resorption, as illustrated in case $\mathrm{I}$.

In cases of calcific myelopathy, removal of the anterior compression is always mandatory. Laminectomy alone does not provide a good outcome in this situation, likely because of persistent anterior compression of the spinal cord. That is why we recommend complementary surgery to allow better neurologic recovery in this situation. Our strategy is to perform this second operation during the initial hospitalization, in the days after the subsequent decompression, when the clinical situation 


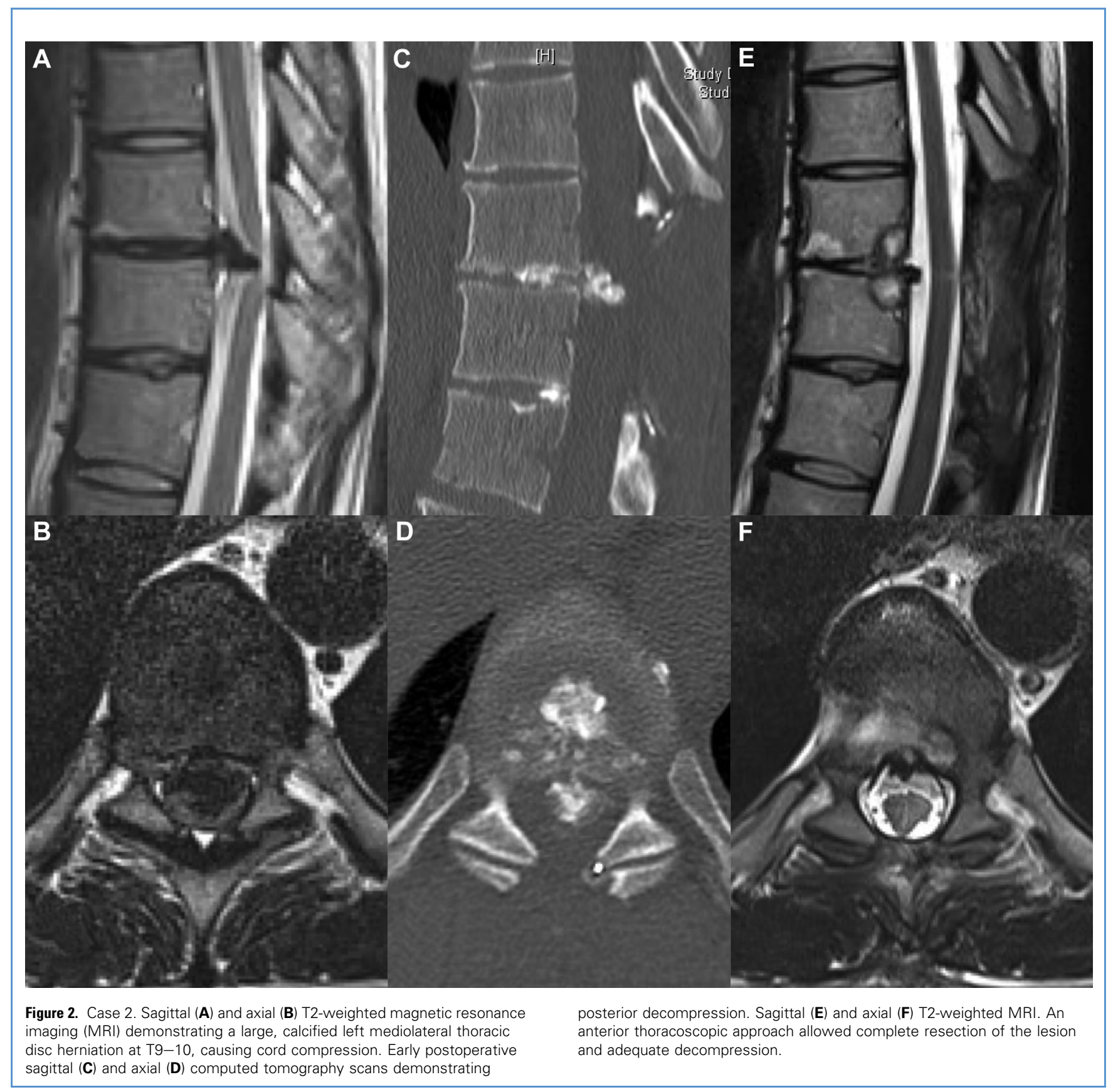

has stabilized. In our series, this was delayed (between II and I7.3 weeks) in 3 patients, however. Two of these patients had undergone surgery in another center and had been referred secondarily for thoracoscopic surgery. The third (patient 5) initially refused complementary surgery, but eventually accepted after neurologic progress stagnated. These 3 patients had favorable final outcomes, and the longer delay between the 2 surgeries had no apparent effect on their long-term prognoses.

\section{CONCLUSION}

Acute thoracic myelopathy on disc herniation is an exceptional condition in relation to 2 anatomoclinical entities: soft and calcified hernias. Although the reason for the rapid onset of severe deficits differs between these 2 entities, our small series suggests that posterior decompression in the acute phase may stabilize or improve the situation in both entities. A complementary hernia resection procedure, which is technically more difficult, must then be discussed, depending on the nature of the lesion (calcified or 
not) and subsequent neurologic recovery. Even if no definitive conclusions can be drawn from this small series, our findings do provide more information on outcomes associated with this disorder. Given the rarity of this condition, a multicenter study is needed to provide new insight into the optimal treatment for these patients.

\section{REFERENCES}

I. Arce CA, Dohrmann GJ. Herniated thoracic disks. Neurol Clin. I985;3:383-392.

2. Carson J, Gumpert J, Jefferson A. Diagnosis and treatment of thoracic intervertebral disc protrusions. J Neurol Neurosurg Psychiatry. I97I;34: 68-77.

3. Mixter WJ, Barr JS. Rupture of the intervertebral disc with involvement of the spinal canal. $\mathrm{N}$ Engl J Med. I934;2II:2I0-2I5.

4. Levi N, Gjerris F, Dons K. Thoracic disc herniation. Unilateral transpedicular approach in 35 consecutive patients. J Neurosurg Sci. 1999;43:37-42 [discussion: 42-43].

5. Delfini R, Di Lorenzo N, Ciappetta P, Bristot R, Cantore G. Surgical treatment of thoracic disc herniation: a reappraisal of Larson's lateral extracavitary approach. Surg Neurol. I996;45: 517-522 [discussion: 522-523].

6. Otani K, Nakai S, Fujimura Y, Manzoku S, Shibasaki K. Surgical treatment of thoracic disc herniation using the anterior approach. J Bone Joint Surg Br. I982;64:340-343.

7. Rosenthal D, Dickman CA. Thoracoscopic microsurgical excision of herniated thoracic discs. J Neurosurg. I998;89:224-235.

8. Cornips EM, Janssen ML, Beuls EA. Thoracic disc herniation and acute myelopathy: clinical presentation, neuroimaging findings, surgical considerations, and outcome. J Neurosurg Spine. 20II; I4:520-528.

9. Fessler RG, Sturgill M. Review: complications of surgery for thoracic disc disease. Surg Neurol. I998; 49:609-6I8.
Io. McCormick WE, Will SF, Benzel EC. Surgery for thoracic disc disease. Complication avoidance: overview and management. Neurosurg Focus. 2000; 9:егз.

II. Chen CF, Chang MC, Liu CL, Chen TH. Acute noncontiguous multiple-level thoracic disc herniations with myelopathy. Spine (Phila Pa 1976). 2004; 29:EI57-EI6o.

12. Harkey HL, Cullom ET, Parent AD. Thoracic disc herniation and paraplegia in Stickler's syndrome. Neurosurgery. I989;24:909-9I2.

I3. Hamilton MG, Thomas HG. Intradural herniation of a thoracic disc presenting as flaccid paraplegia: case report. Neurosurgery. I990;27:482-484.

I4. Lyu RK, Chang HS, Tang LM, Chen ST. Thoracic disc herniation mimicking acute lumbar disc disease. Spine (Phila Pa 1976). I999;24:4I6-4I8.

I5. Sasaki S, Kaji K, Shiba K. Upper thoracic disc herniation followed by acutely progressing paraplegia. Spinal Cord. 2005;43:74I-745.

I6. Ueda Y, Kawahara N, Murakami H, Demura S, Tsuchiya H. Thoracic disk herniation with paraparesis treated with transthoracic microdiskectomy in a I4-year-old girl. Orthopedics. 20I2; 35:e $774-\mathrm{e} 777$.

I7. Miyakoshi N, Hongo M, Kasukawa Y, Ishikawa Y, Shimada Y. Posteriorly migrated thoracic disc herniation: a case report. J Med Case Rep. 2013;7:4I.

I8. Yue B, Chen B, Zou YW, Xi YM, Ren XF, Xiang HF, et al. Thoracic intervertebral disc calcification and herniation in adults: a report of two cases. Eur Spine J. 20I6;25(Suppl I):II8-I23.

I9. Guest JD, Griesdale DE, Marotta T. Thoracic disc herniation presenting with transient anterior spinal artery syndrome: a case report. Interv Neuroradiol. 2000;6:327-33I.
20. Reynolds JM, Belvadi YS, Kane AG Poulopoulos M. Thoracic disc herniation leads to anterior spinal artery syndrome demonstrated by diffusion-weighted magnetic resonance imaging (DWI): a case report and literature review. Spine J. 20I4;I4:e17-e22.

2I. Fehlings MG, Perrin RG. The timing of surgical intervention in the treatment of spinal cord injury: a systematic review of recent clinical evidence. Spine (Phila Pa 1976). 2006;3I(II Suppl):S28-S35 [discussion: $\mathrm{S}_{3} 6$ ].

22. Dickman CA, Rosenthal D, Regan JJ. Reoperation for herniated thoracic discs. J Neurosurg. I999;9I(2 Suppl):I57-I62.

23. Wang H, Ma L, Xue R, Yang D, Wang T, Wang Y, et al. The incidence and risk factors of postoperative neurological deterioration after posterior decompression with or without instrumented fusion for thoracic myelopathy. Medicine (Baltimore). 2016;95:e5519.

Conflict of interest statement: The authors declare that the article content was composed in the absence of any commercial or financial relationships that could be construed as a potential conflict of interest. 